Research Article

\title{
Optimal Design Method for Inner-Intrinsically Safe Buck-Boost Converters Based on Ignition Capability
}

\author{
Yongxiu Zhao $\mathbb{D}$, Minggeng Li $\mathbb{D}$, and Qi Wang $(\mathbb{D}$ \\ School of Electrical and Control Engineering, Xi'an University of Science \& Technology, Xi'an 710054, China \\ Correspondence should be addressed to Qi Wang; 18206204069@stu.xust.edu.cn
}

Received 18 December 2020; Revised 29 January 2021; Accepted 5 February 2021; Published 24 February 2021

Academic Editor: Paolo Manfredi

Copyright (C) 2021 Yongxiu Zhao et al. This is an open access article distributed under the Creative Commons Attribution License, which permits unrestricted use, distribution, and reproduction in any medium, provided the original work is properly cited.

\begin{abstract}
Intrinsically safe switching converters are the best choice for low-voltage DC power supplies in explosive environments (such as coal mine). To obtain the optimal design method of the inner-intrinsically safe buck-boost converter (IISBBC), the equivalent circuits for various switching states and operating conditions of the buck-boost converter are studied, and the most dangerous inductor-disconnected discharge (IDD) condition of the buck-boost converter is obtained. Based on this condition, the IDD behavior of the IISBBC is studied. According to the minimum ignition curves (MICs) of the resistive circuit and the simple inductive circuit, the expressions describing the IDD ignition capability of the IISBBC in terms of the critical ignition power and the critical ignition energy are derived. The IDD has the strongest ignition capability based on power when the IISBBC is working at its maximum input voltage and minimum load resistance, and it has the strongest ignition capability based on energy when the IISBBC is working at its minimum input voltage and minimum load resistance. The converter is inner-intrinsically safe only when the maximum arc power is less than the critical ignition power and the inductive energy is less than its critical value. By incorporating the proposed criterion, the optimal design method for IISBBCs that meets the demands of electric and inner-intrinsic safety performance is obtained. Based on this method, the design range of the inductance and capacitance and the optimal inductance to give the IISBBC the best inner-intrinsic safety performance are obtained. The feasibility and reliability of the proposed optimal design method are demonstrated by an explosion test.
\end{abstract}

\section{Introduction}

Electrical equipment working in explosive environments must meet explosion-proof requirements, and the intrinsically safe type is the best type of explosion-proofing $[1,2]$. With the development of modern industrial control systems for integration and low power consumption, buck-boost converters are the best choice for intrinsically safe power supply because of their advantages of boost or buck output, small size, light weight, and high conversion efficiency.

The inner-intrinsically safe buck-boost converter (IISBBC) must not ignite explosive gases when an inductordisconnected discharge (IDD) occurs [3-5]. Intrinsic safety is achieved by limiting the ignition capability of components in the IISBBC [6-10]. Therefore, research on the design and optimization of the IISBBC is needed.
The design principle of the IISBBC is to meet the demands of both inner-intrinsic safety and electric performance [11]. The optimal topology design methods for the buck-boost converter have been researched [12-14], and the control strategies for the buck-boost converter have also been studied $[15,16]$. However, the intrinsically safe performance of buck-boost converters has not been considered.

Presently, ignition capability can be evaluated by nonexplosive and explosive evaluation methods. The explosive evaluation method is accurate and reliable, but it cannot guide the design of an IISBBC. The nonexplosive evaluation method is more suitable for the analysis and design of an IISBBC. At present, the IDD ignition capability is largely described in terms of the minimum ignition energy [17-20] and the average discharge power [21]. However, the minimum ignition energy cannot explain why an IDD with a longer discharge time has a weaker ignition capability. The 
ignition capability evaluation according to the average discharge power is affected by the energy loss factor, which reduces the reliability of the evaluation result. Moreover, the above studies cannot be applied to time-varying nonlinear circuits such as buck-boost converters [22]. Thus, the most dangerous output short-circuit discharge conditions and the design methods of output intrinsically safe buck-boost converters have been studied [23]. However, inner-intrinsic safety was not considered, which means that output intrinsic safety converters must be equipped with an explosion-proof enclosure, which causes them to lose the advantages of intrinsic safety. The design method for intrinsically safe buck-boost converters was based on minimum ignition curves (MICs) [24]. However, this method is complicated, and large errors may arise.

To obtain a reliable and feasible optimal design method for the IISBBC, equivalent circuits in different switching states and operating modes of buck-boost converters were analyzed. The most dangerous IDD conditions were obtained. The relationship between the IDD characteristics and converter parameters was then analyzed in depth. Based on the MIC of a resistive circuit and a simple inductive circuit, expressions describing the IDD ignition capability of the buck-boost converter will be derived. Then, the design method for an IISBBC meeting the demands of both innerintrinsic safety and electric performance will be obtained. Based on the principle of the maximum safety margin of the inner-intrinsic safety, the optimal method will be obtained. The feasibility and reliability of the proposed optimal design method will be evaluated by the explosion criterion based on the International Electrotechnical Commission (IEC) spark test apparatus.

\section{Design Consideration Based on Electric Performance Demand}

2.1. Operating Modes of Buck-Boost Converters. The buckboost converter schematic is shown in Figure 1, where $U_{i}$ represents the input voltage, $U_{\mathrm{o}}$ represents the output voltage, $I_{\mathrm{o}}$ represents the output current, $S$ represents the switch, $L$ represents the inductance, VD represents the diode, $C$ represents the capacitance, $R_{\mathrm{L}}$ represents the load resistance, and $f$ represents the switching frequency.

$$
L_{\mathrm{C}}=\frac{R_{\mathrm{L}}(1-d)^{2}}{2 f}=\frac{R_{\mathrm{L}} U_{i}^{2}}{2 f\left(U_{\mathrm{i}}+U_{\mathrm{o}}\right)^{2}},
$$

If the inductance current $i_{\mathrm{L}}$ drops to zero during a switching cycle, the buck-boost converter operates in the discontinuous conduction mode (DCM); otherwise, it operates in the continuous conduction mode (CCM). The critical inductance of the CCM and DCM, $L_{C}$ is given by [24].where $d$ represents the switching duty cycle. If $L>L_{C}$, the converter works in the CCM; if $L<L_{C}$, it works in the DCM. The inductance peak current $I_{L P}$ of the converter in the CCM and DCM are given by [24].

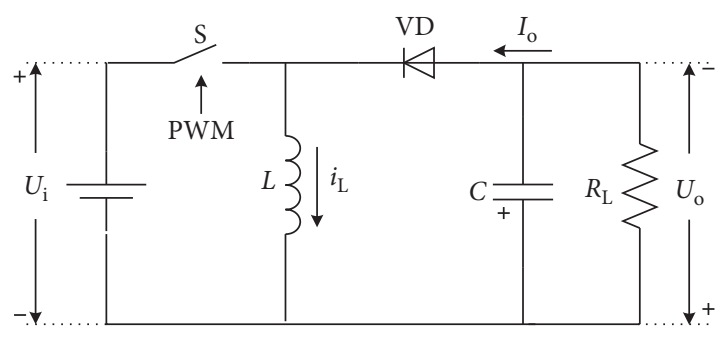

Figure 1: The schematic diagram of the buck-boost converter.

$$
\begin{aligned}
I_{L P C C M} & =\frac{U_{\mathrm{o}}\left(U_{\mathrm{i}}+U_{\mathrm{o}}\right)}{R_{\mathrm{L}} U_{\mathrm{i}}}+\frac{U_{\mathrm{o}} U_{\mathrm{i}}}{2 L f\left(U_{\mathrm{i}}+U_{\mathrm{o}}\right)}, \\
I_{L P D C M} & =U_{\mathrm{o}} \sqrt{\frac{2}{L f R_{\mathrm{L}}}},
\end{aligned}
$$

where $I_{L P C C M}$ represents the inductance peak current in the CCM and $I_{L P D C M}$ represents the inductance peak current in the DCM. From equations (2) and (3), $I_{L \mathrm{PCCM}}$ decreases with increasing $U_{\mathrm{i}}, L$, and $R_{L}$ in the CCM; $I_{L P D C M}$ is independent of $U_{\mathrm{i}}$ and decreases with increasing $R_{L}$ and $L$ in the DCM.

The laws governing the change in $I_{L P}$ with $L$ in different operating modes according to equations (2)-(3) are shown in Figure 2.

If the inductance valley current $I_{\mathrm{LV}}$ is always larger than the output current $I_{\mathrm{o}}$ in a switching cycle, the buck-boost converter operates in the complete inductance supply mode (CISM); otherwise, it operates in the incomplete inductance supply mode (IISM). The critical inductance $L_{\mathrm{K}}$ of the CISM and IISM [24] is given by the following:

$$
L_{\mathrm{K}}=\frac{R_{L}(1-d)^{2}}{2 f d}=\frac{R_{L} U_{i}^{2}}{2 f U_{\mathrm{o}}\left(U_{\mathrm{i}}+U_{\mathrm{o}}\right)},
$$

when $L>L_{\mathrm{K}}$, the converter works in the CISM; when $L<L_{\mathrm{K}}$, it works in the IISM. Substituting equation (1) into (4), it is obvious that $L_{\mathrm{C}}$ is always smaller than $L_{\mathrm{K}}$; therefore, the operating modes of the buck-boost converter according to $L$ are shown in Figure 3.

As shown in Figure 3, the buck-boost converter has three operating modes: CCM-CISM, CCM-IISM, and DCMIISM. The output ripple voltages $U_{\mathrm{PP}}$ of the buck-boost converter in these three operating modes are given by [23]:

$$
\begin{gathered}
U_{\text {PP.CCM-CISM }}=\frac{U_{o}^{2}}{R_{L} C f\left(U_{\mathrm{o}}+U_{\mathrm{i}}\right)}, \\
U_{\text {PP.CCM-IISM }}=\frac{L U_{\mathrm{o}}}{2 C R_{L}}\left[\frac{U_{\mathrm{o}}}{U_{\mathrm{i}}}+\frac{R_{L} U_{\mathrm{i}}}{2 L f\left(U_{\mathrm{o}}+U_{\mathrm{i}}\right)}\right]^{2}, \\
U_{\text {PP.DCM-IISM }}=\frac{U_{\mathrm{o}}}{f C R_{L}}\left(1-\sqrt{\frac{2 L f}{R_{L}}}+\frac{L f}{2 R_{L}}\right) .
\end{gathered}
$$

The laws governing the change in $U_{\mathrm{PP}}$ with $L$ in different operating modes according to equations (5)-(7) are shown in Figure 4. 


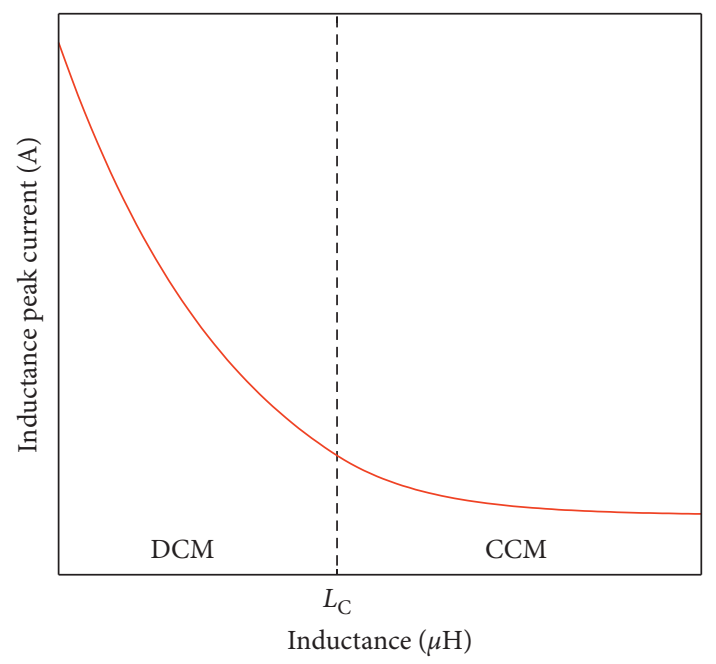

FIGURE 2: $I_{L P}$ vs. $L$ in different operating modes.

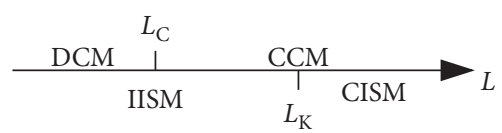

Figure 3: Operating modes vs. $L$.

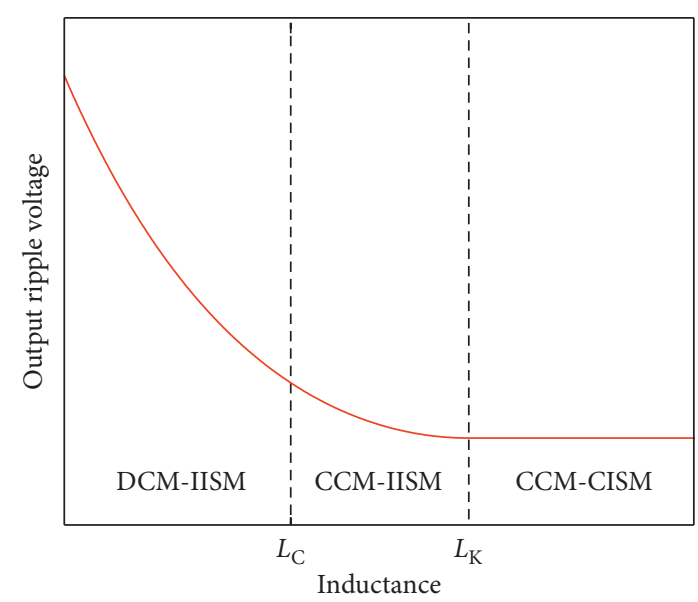

Figure 4: $U_{\mathrm{PP}}$ vs. $L$ in different operating modes.

According to Figure 4, $U_{\mathrm{PP}}$ decreases with increasing $L$ in the IISM and $U_{\mathrm{PP}}$ is independent of $L$ in the CISM.

\subsection{Inductance Design Based on Electric Performance} Demands. According to Figure 3, L affects the operating modes in which the buck-boost converter works. Assuming that the range of $U_{i}$ is $\left[U_{i \min }, U_{i \max }\right]$ and the range of $R_{L}$ is [ $\left.R_{L \text { min }}, R_{L \text { max }}\right]$, the laws of the changes in the operating modes with $L, U_{\mathrm{i}}$, and $R_{L}$ are shown in Figure 5.

In Figure 5, $L_{1}>L_{2}>L_{3}>L_{4}$, and the shaded area indicates that the converter is working in the CCM, and in the other areas, it works in the DCM. The larger the inductance $L$ is, the larger the area in which the converter operates in the CCM. For each figure, the inductance

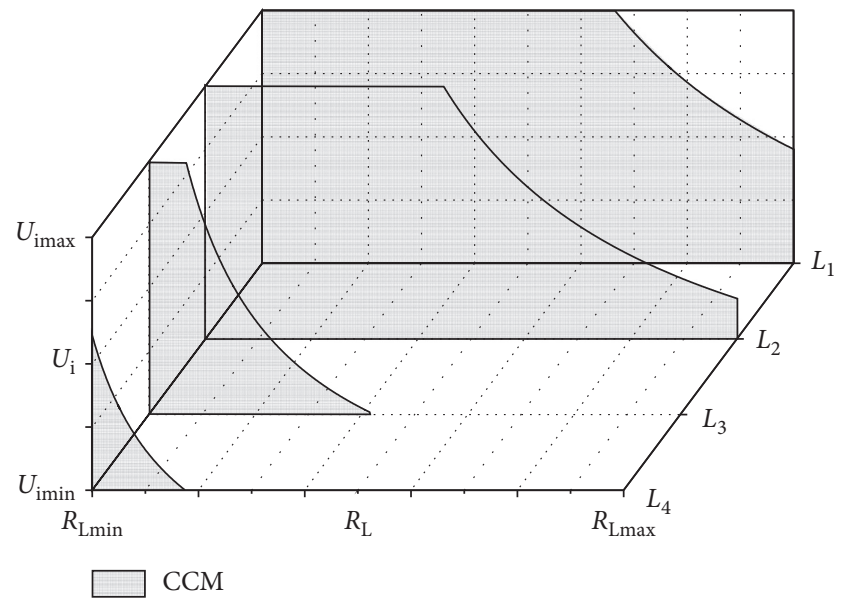

Figure 5: Operating modes vs. $L, U_{i}$ and $R_{L}$.

valley current $I_{L V}$ decreases as $R_{L}$ and $U_{\mathrm{i}}$ increase, and after it drops to zero completely, the converter's operating mode changes from the CCM to the DCM. According to equations (2)-(3) and Figure 4, $I_{L P}$ and the current stress of the switch will be too large if the converter always works in the DCM in the assumed $U_{\mathrm{i}}-R_{L}$ area. Moreover, $I_{L P}$ increases with increasing $I_{o}$. Therefore, to ensure that $I_{L P}$ will not be too large when $I_{o}$ is large, the converter is better designed to work in the CCM at least when the output current $I_{o}$ reaches the maximum. In this case, the operating mode within the assumed $U_{\mathrm{i}}-R_{L}$ working area is shown in Figure 6.

Thus, the minimum inductance that meets the electric performance demands $L_{E \text { min }}$ is $L_{C}$ when the converter works at $U_{i \max }$ and $R_{L \text { min }}$. According to equation (1), $L_{E \min }$ is given by the following:

$$
L_{E \min }=\frac{R_{L \min } U_{i \max }^{2}}{2 f\left(U_{i \max }+U_{\mathrm{o}}\right)^{2}} .
$$

\subsection{Capacitance Design Based on Electric Performance} Demands. After the inductance is determined, the capacitance should be determined based on the maximum output ripple voltage $U_{\mathrm{PP} \max }$ in the assumed $U_{\mathrm{i}}-R_{L}$ working area to meet the electric performance demand. If the converter works in the CCM when the output power is large (such as in the case of $L_{3}$ in Figure 5), the maximum output ripple voltage $U_{\mathrm{PP} \max }$ is obtained when the converter works at $U_{i \max }$ and $R_{L \text { min }}$ in the CCM-IISM. Thus, the minimum capacitance $C_{E \text { min }}$ that can meet the electric performance demand is given by [25]:

$$
C_{E \text { min }}=\frac{L}{2 m R_{L \min }^{2}}\left[\frac{U_{\mathrm{o}}}{U_{i \min }}+\frac{R_{L \min } U_{i \min }}{2 L f\left(U_{i \min }+U_{\mathrm{o}}\right)}\right]^{2},
$$

where $m=U_{\mathrm{PP} \max } / U_{\mathrm{o}}$. The change laws for $C_{E \text { min }}$ according to $L$ and $m$ are shown in Figure 7 .

According to Figure 7 , the larger $U_{\mathrm{PP} \max }$ is, the lower $C_{E \min }$ is. $C_{E \min }$ decreases first and then increases with increasing $L$. 


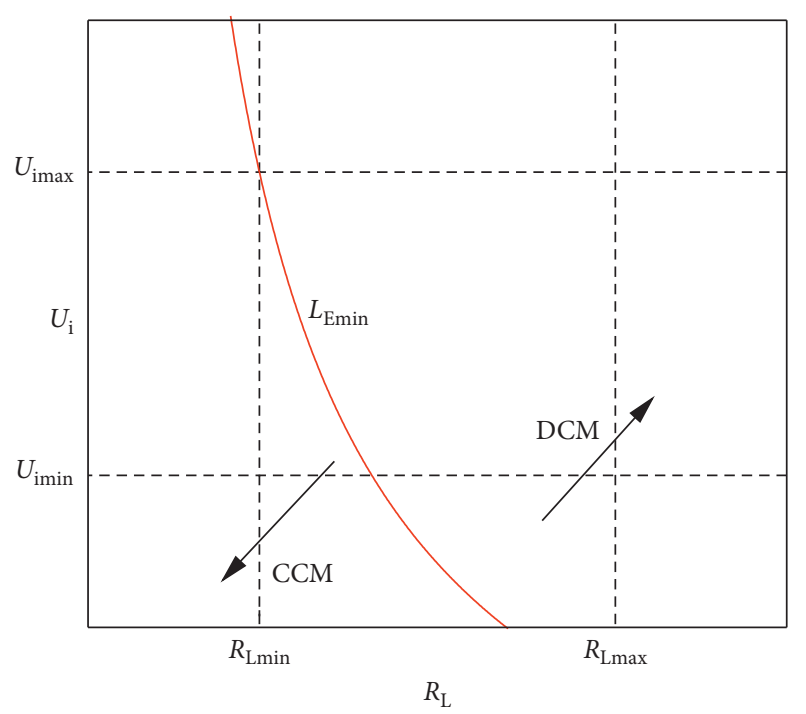

FIgURE 6: Operating mode to meet electric performance.

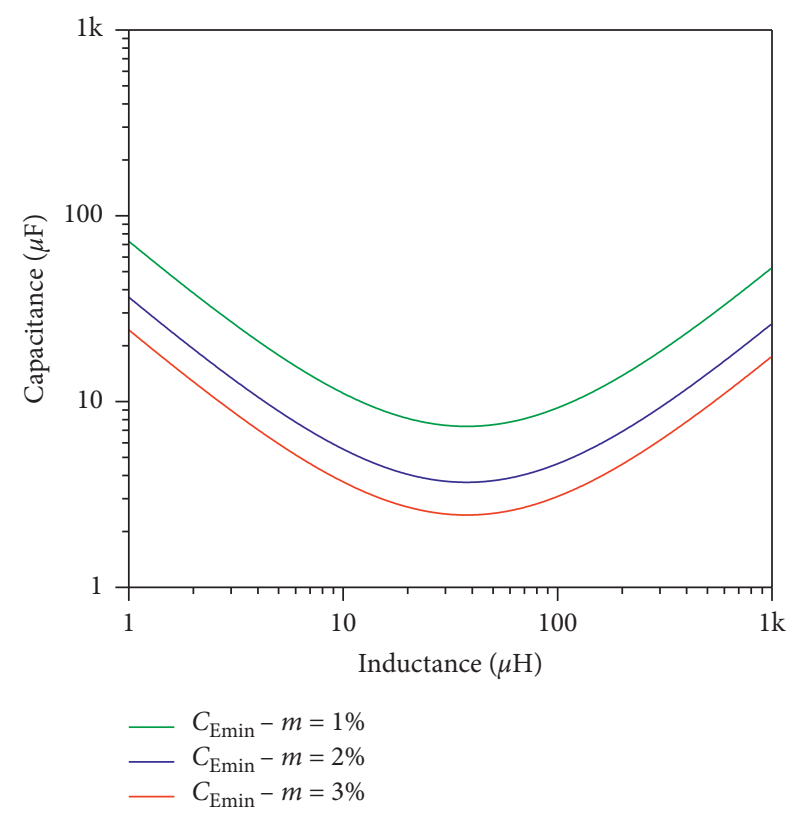

Figure 7: $C_{E \min }$ vs. $L$ and $m$.

\section{Design Consideration Based on the Inner- Intrinsic Safety Demand}

The buck-boost converter is a time-varying and nonlinear circuit with multiple operating modes. Therefore, it is necessary to analyze its operating characteristics to obtain the most dangerous IDD condition and the IDD characteristics in this condition.

3.1. The Most Dangerous Condition of the Inductor-Disconnected Discharge. The buck-boost converter has two equivalent circuits according to the switching state, as shown in Figure 8.
Figure 8 shows that the arc energy $W_{\text {arc }}$ is provided by the power source and the inductance in the switch-on state; thus, the switch-on state arc energy $W_{\text {arc.on }}$ is as follows:

$$
W_{\text {arc.on }}=W_{U_{\mathrm{i}}}+W_{L},
$$

where $W_{U i}$ represents the arc energy provided by the power supply and $W_{L}$ represents the inductive energy.

In the switch-off state, $W_{L}$ supplies the arc, $C$, and $R_{L}$. Thus, the switch-off state arc energy $W_{\text {arc.off }}$ is given as follows:

$$
W_{\text {arc.off }}=W_{L}-W_{R C}
$$

where $W_{R C}$ represents the energy consumed by $C$ and $R_{L}$.

Comparing equations (10) and (11), it can be seen that when the IDD occurs completely in the switch-on state, $W_{\text {arc }}$ is maximized, and the inductive energy $W_{L}$ is entirely supplied to the arc. $W_{L}$ can be expressed as follows:

$$
W_{L}=\frac{1}{2} L i_{L}^{2}
$$

where $i_{L}$ represents the inductance current. According to equation (12), if $i_{L}$ is equal to $I_{L P}, W_{\text {arc }}$ is equal to the maximum arc energy $W_{\text {arcmax }}$. Therefore, the most dangerous IDD condition of the buck-boost converter is that IDD occurs when $i_{L}$ is equal to $I_{L P}$, and the switch remains in the switch-on state.

3.2. Maximum Inductor-Disconnected Discharge Characteristics. Based on the above analysis, the most dangerous IDD condition of the buck-boost converter is obtained. The IDD ignition capability is strongest in the most dangerous IDD condition. Therefore, research on IDD behavior in the most dangerous condition is necessary.

In the most dangerous IDD condition, the buck-boost converter is equivalent to a simple inductive circuit with wire resistance. The typical arc voltage $u_{\text {arc }}$ and arc current $i_{\text {arc }}$ waveforms of the simple inductive circuit based on the IEC spark test apparatus are shown in Figure 9.

In Figure 9, $T$ represents the arc discharge time, $u_{\text {arc.max }}$ represents the maximum arc voltage, $i_{\text {arcmax }}$ represents the maximum arc current, and $u_{\text {arc.min }}$ represents the minimum arc voltage, which is mainly determined by the electrode material and is approximately $10 \mathrm{~V}$ in the IDD based on the IEC spark test apparatus. According to the change trend of $u_{\text {arc }}$, the IDD can be divided into three stages:

(I) Arc-building stage: the electrode begins to break, the voltage at the breaking point rises rapidly from zero to the minimum arcing voltage, and the arc is formed.

(II) Arc-discharging stage: at this stage, $u_{\text {arc }}$ rises to $u_{\text {arcmax }}$, and $i_{\text {arc }}$ drops to approximately zero. The process is mainly affected by the circuit parameters.

(III) Glow-discharging stage: the arc is basically extinguished, and the remaining energy (if any) oscillates back and forth between the equivalent capacitance between the inductance and the 


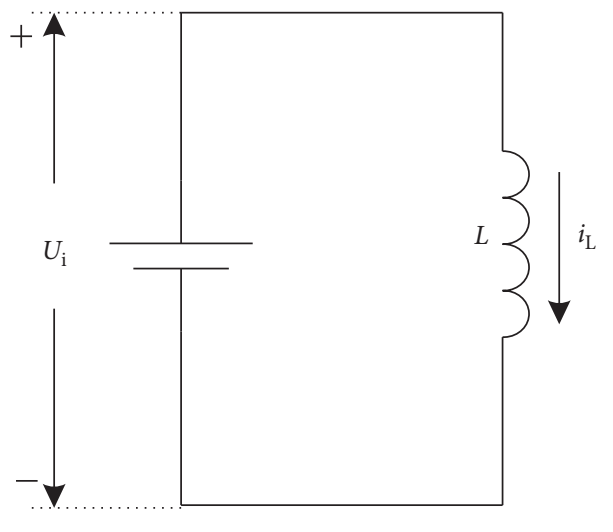

(a)

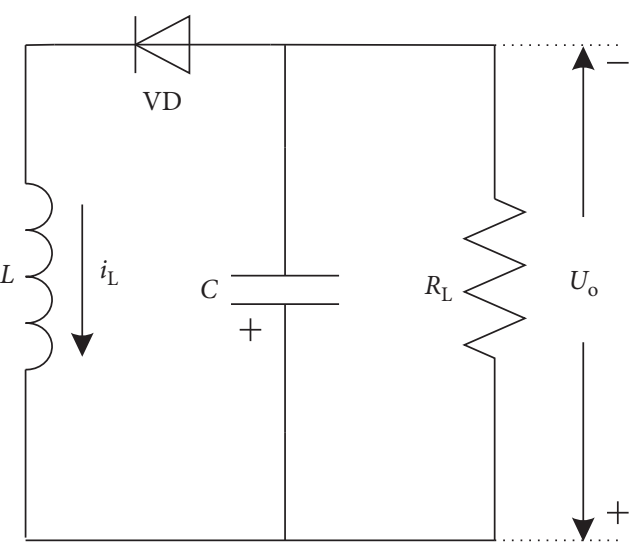

(b)

FIGURE 8: Equivalent circuits of the buck-boost converter. (a) Switch on. (b) Switch off.

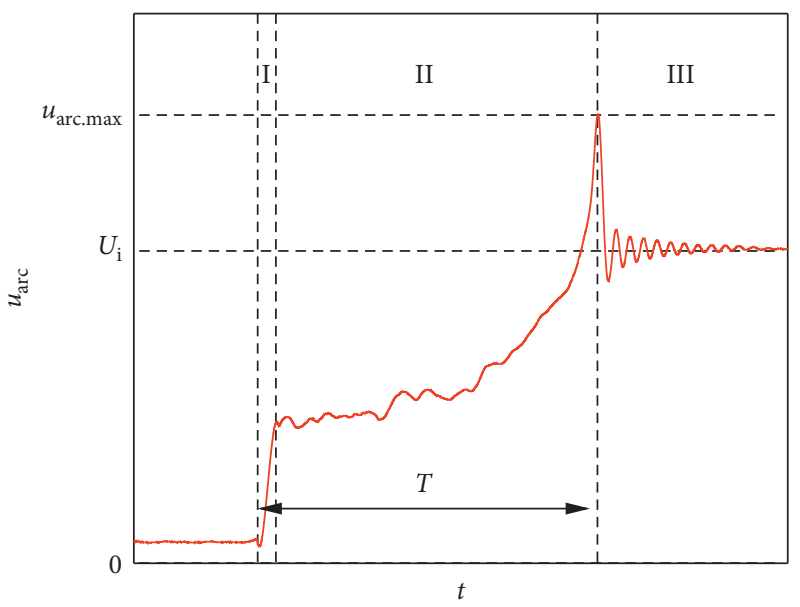

(a)

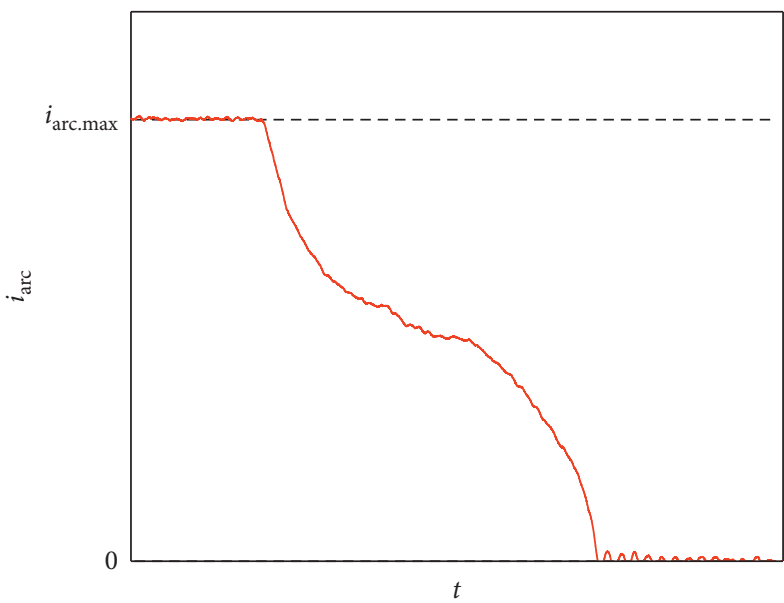

(b)

Figure 9: Typical IDD volt-amp waveform. (a) Arc voltage. (b) Arc current.

breaking electrode and is eventually consumed in the circuit resistance.

Since $i_{\text {arc }}$ is approximately zero in stage III, the release of arc energy and the generation of Joule heat mainly occur in stages I and II. In these two stages, $u_{\text {arc }}$ increases from zero to $u_{\text {arcmax }}$ and finally equals $U_{\mathrm{i}}$, whereas $i_{\text {arc }}$ decreases from $i_{\text {arcmax }}$ to zero. Therefore, $u_{\text {arc.max }}$ and $i_{\text {arcmax }}$ of the buckboost converter in the most dangerous IDD condition are given by the following:

$$
\begin{aligned}
& u_{\text {arc.max }}=\max \left\{U_{\mathrm{i}}+\left|U_{L}\right|\right\}=\max \left\{U_{\mathrm{i}}+\left|L \frac{\mathrm{d} i_{\mathrm{arc}}}{\mathrm{d} t}\right|\right\}, \\
& i_{\text {arc max }}=I_{L P},
\end{aligned}
$$

where $U_{L}$ represents the IDD inductor voltage. However, $u_{\text {arcmax }}$ is random. Based on the linear attenuation model, it can be assumed that $i_{\text {arc }}$ decreases linearly from $I_{L P}$ to zero within the discharge time $T$; thus, equation (13) can be simplified as follows:

$$
u_{\text {arc } \max }=U_{\mathrm{i}}+L \frac{I_{L P}}{T} .
$$

According to equations (14) and (15), the maximum arc power $P_{\text {arc.max }}$ is given by the following:

$$
P_{\text {arc.max }}=u_{\text {arc.max }} i_{\text {arc max }}=U_{\mathrm{i}} I_{L P}+L \frac{I_{L P}^{2}}{T} .
$$

3.3. Critical Ignition Power of the Inductor-Disconnected Discharge. The maximum arc power $P_{\text {arcmax }}$ of the buckboost converter is obtained. Although the arc power $P_{\text {arc }}$ used in the test is random, it will never be greater than $P_{\text {arc.max }}$. If $P_{\text {arc.max }}$ has the capability to ignite explosive gases, $P_{\text {arc }}$ used in the test will also have a chance of igniting explosive gases. Therefore, the inner-intrinsic safety performance of the buck-boost converter can be judged according to whether $P_{\text {arcmax }}$ has the capability to ignite explosive gases. 
The change laws for the minimum ignition current $I_{\mathrm{MIC}}$ for $U_{\mathrm{i}}$ can be obtained from the Type I MIC of the resistive circuit [26]. Based on power function regression analysis, the relationship between $I_{\mathrm{MIC}}$ and $U_{\mathrm{i}}$ is approximately given by the following:

$$
I_{\mathrm{MIC}}=22.35\left(V_{i}-14\right)^{-1.24} .
$$

Comparing $I_{\mathrm{MIC}}$ obtained by equation (17) and the Type I MIC of the resistive circuit under different $U_{\mathrm{i}}$, the results are shown in Table 1.

According to Table 1, the relative errors of $I_{\text {MIC }}$ obtained by equation (17) and the Type I MIC of the resistive circuit are less than $\pm 5 \%$, which proves the feasibility and accuracy of equation (17). According to equation (17), the critical ignition power $P_{\mathrm{CI}}$ of the resistive circuit is given by the following:

$$
P_{\mathrm{CI}}=U_{\mathrm{i}} I_{\mathrm{MIC}}=\left(12.25 I_{\mathrm{MIC}}^{(25 / 31)}+14\right) I_{\mathrm{MIC}} .
$$

According to Figure 8(a) and equation (13), the buckboost converter in the most dangerous IDD condition can be taken as the equivalent to the resistive circuit consisting of the input voltage source $U_{\mathrm{i}}$, the controlled voltage source $U_{L}=L d i_{\mathrm{arc}} / \mathrm{d} t$, and the wire resistance $R_{\text {wire }}$ shown in Figure 10.

In Figure 10, $G$ is the discharge electrode. Based on the proposed equivalent circuit, if $P_{\text {arcmax }}$ is greater than $P_{\mathrm{CI}}$, the IDD of the buck-boost converter will have the capability to ignite methane-air mixtures. Combining equations (15) and (18), the following can be derived:

$$
U_{\mathrm{i}} I_{L P}+L \frac{I_{L P}^{2}}{T}=P_{\text {arc } \max } \leq P_{\mathrm{CI}}=\left(12.25 I_{L P}^{-(25 / 31)}+14\right) I_{L P} .
$$

If equation (19) holds, then the buck-boost converter is inner-intrinsically safe based on the arc power; otherwise, it is dangerous. To explore the influence of the converter parameters on the ignition capability based on the arc power, the change laws of $P_{\text {arc.max }}$ and $P_{\mathrm{CI}}$ in terms of $U_{\mathrm{i}}, R_{L}$, and $L$ are shown in Figure 11.

When $P_{\text {arcmax }}<P_{\mathrm{CI}}$, the buck-boost converter is an inner-intrinsically safe converter; when $P_{\mathrm{arcmax}} \geq P_{\mathrm{CI}}$, the converter will have the capability to ignite methane-air mixtures, and the greater the difference is between $P_{\text {arc.max }}$ and $P_{\mathrm{CI}}$, the stronger the ignition capability.

According to Figure 11, $P_{\mathrm{CI}}$ decreases with increasing $L$ and $R_{L}$, is independent of $U_{\mathrm{i}}$ in the DCM, and decreases with increasing $U_{\mathrm{i}}$ in the CCM.

$P_{\text {arc.max }}$ decreases with increasing $R_{L}$, increases with increasing $U_{\mathrm{i}}$ when $L$ is small, decreases with increasing $U_{\mathrm{i}}$ when $L$ is large, and first decreases and then increases with increasing $L$. Therefore, the IDD ignition capability is
TABLE 1: Errors of $\mathrm{I}_{\mathrm{MIC}}$ between regression expression and MIC.

\begin{tabular}{lccc}
\hline $\begin{array}{l}U_{i} \\
(\mathrm{~V})\end{array}$ & $\begin{array}{c}I_{\mathrm{MIC}} \text { by equation (17) } \\
(\mathrm{A})\end{array}$ & $\begin{array}{c}I_{\mathrm{MIC}} \text { by MIC } \\
(\mathrm{A})\end{array}$ & Relative error (\%) \\
\hline 20 & 2.423 & 2.35 & 3.11 \\
30 & 0.718 & 0.74 & -2.97 \\
40 & 0.393 & 0.41 & -4.14 \\
50 & 0.263 & 0.26 & 1.15 \\
60 & 0.194 & 0.185 & 4.86 \\
70 & 0.152 & 0.145 & 4.83 \\
80 & 0.124 & 0.12 & 3.33 \\
90 & 0.104 & 0.105 & -0.95 \\
100 & 0.089 & 0.088 & 1.14 \\
200 & 0.034 & 0.033 & 3.03 \\
\hline
\end{tabular}

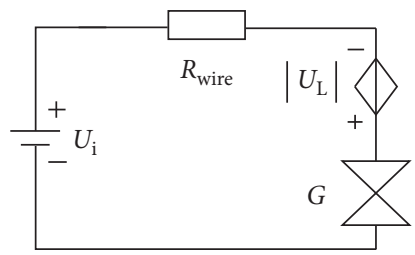

FIGURE 10: Equivalent resistive circuit of the buck-boost converter in the most dangerous IDD condition.

strongest when the converter operates at $U_{i \max }$ and $R_{L \text { min }}$ based on the arc power.

3.4. Critical Ignition Energy of the Inductor-Disconnected Discharge. For the IDD of the buck-boost converter, the effect of the arc energy on the ignition capability should also be analyzed.

According to equation (12), $W_{L}$ is affected by $L$ and $i_{L}$. The minimum ignition current $I_{\text {MIC }}$ with different values of inductance $L$ can be obtained from the Type I MIC of the simple inductive circuit [26]. Suppose $W_{\text {arc }}$ is equal to the critical ignition energy $W_{\mathrm{CI}}$; then, according to equations (10) and (12), the critical inductive energy $W_{\mathrm{LCI}}$ is given by the following:

$$
W_{\mathrm{LCI}}=\frac{1}{2} L I_{\mathrm{MIC}}^{2}=W_{\mathrm{CI}}-W_{U_{\mathrm{i}}} .
$$

According to the Type I MIC of the simple inductive circuit, when $I_{L P}<0.4 \mathrm{~A}$, the energy provided by the power source $W_{\mathrm{Ui}}$ is negligible; thus, $W_{\text {arc }}$ is mainly provided by $L$, so $W_{\mathrm{LCI}}$ is approximately constant at $525 \mu \mathrm{J}$; when $I_{L P} \geq 0.4$ $\mathrm{A}, W_{\mathrm{LCI}}$ is not constant. In this condition, $W_{\mathrm{LCI}}$ decreases with increasing $U_{\mathrm{i}}$ when $U_{\mathrm{i}}<18 \mathrm{~V}$, and $W_{\mathrm{LCI}}$ is independent of $U_{\mathrm{i}}$ when $U_{\mathrm{i}} \geq 18 \mathrm{~V}$. Therefore, based on the power function regression analysis, the change laws of $W_{\text {LCI }}$ with $U_{\mathrm{i}}$ and $I_{L P}$ are given by the following: 


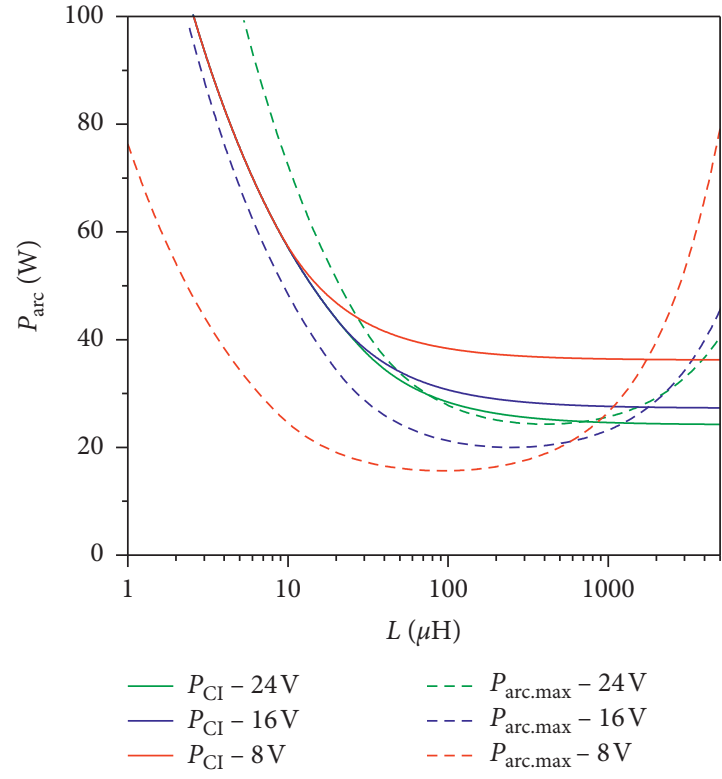

(a)

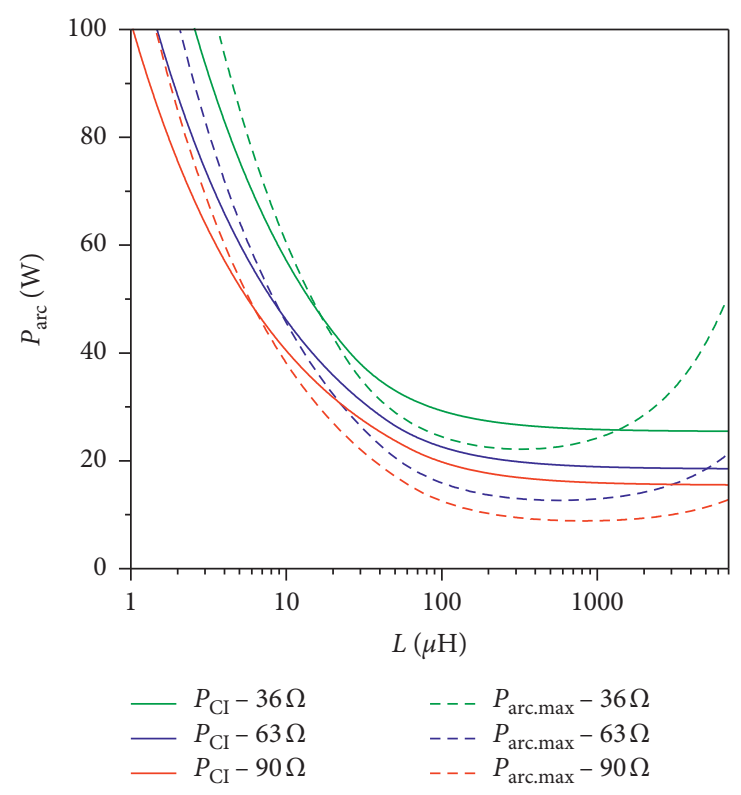

(b)

Figure 11: $P_{\text {arc.max }}$ and $P_{\mathrm{CI}}$ vs. $L$. (a) Different $U_{i}\left(T=200 \mu \mathrm{s}, U_{o}=18 \mathrm{~V}, R_{L}=36 \Omega\right.$, and $\left.f=200 \mathrm{kHz}\right)$. (b) Different $R_{L}\left(T=200 \mu \mathrm{s}, U_{o}=18 \mathrm{~V}\right.$, $U_{i}=20 \mathrm{~V}$, and $f=200 \mathrm{kHz}$ ).

$$
W_{\mathrm{LCI}}= \begin{cases}525 \times 10^{-6,} & \left(I_{L P}<0.4 \mathrm{~A}\right), \\ 3.28 I_{L P}^{2}\left(2.5 I_{L P}\right)^{-1.596-0.012 \exp \left(0.187 U_{\mathrm{i}}\right)} \times 10^{-3}, & \left(I_{L P} \geq 0.4 \mathrm{~A}, U_{\mathrm{i}}<18 \mathrm{~V}\right), \\ 0.55 I_{L P}^{0.05} \times 10^{-3}, & \left(I_{L P} \geq 0.4 \mathrm{~A}, U_{\mathrm{i}} \geq 18 \mathrm{~V}\right) .\end{cases}
$$

Comparing $W_{\text {LCI }}$ obtained by equation (21) and the Type I MIC of the simple inductive circuit under different $U_{i}$ and $I_{L P}$, the results are shown in Table 2 .

According to Table 2, the relative errors of $W_{\mathrm{LCI}}$ obtained by equation (21) and the Type I MIC of the simple inductive circuit are less than $\pm 5 \%$, which proves the feasibility and accuracy of equation (21). Equation (21) shows that if $W_{L}<W_{\mathrm{LCI}}$, the buck-boost converter will be innerintrinsically safe based on the arc energy.

To investigate the influence of the converter parameters on the ignition capability based on the arc energy, the change laws of $W_{L}$ and $W_{\text {LCI }}$ with $U_{i}, R_{L}$, and $L$ are shown in Figure 12.

According to Figure 12, $W_{\text {LCI }}$ and $W_{L}$ decrease with increasing $U_{\mathrm{i}}$ and $R_{L} ; W_{\mathrm{LCI}}$ decreases and tends to be stable with increasing $L ; W_{L}$ increases with increasing $L$ and $I_{L P}$ and decreasing $U_{\mathrm{i}}$. Therefore, the IDD ignition capability is strongest when the converter operates at $U_{i \text { min }}$ and $R_{L \text { min }}$ based on the arc energy. It can also be concluded that in lowvoltage and large-current conditions, $W_{\mathrm{LCI}}$ is not constant but changes with $U_{\mathrm{i}}$ and $I_{L P}$ only when $I_{L P}<0.4 \mathrm{~A}$ is $W_{\mathrm{LCI}}$ equal to $525 \mu \mathrm{J}$. This is consistent with the conclusions regarding the Type I MIC of the simple inductive circuit.

3.5. Inductance Design Based on Inner-Intrinsic Safety Demands. According to Figure 11, there is a maximum inductance $L_{P \max }$ and a minimum inductance $L_{P \min }$ based on power, which are shown in Figure 13.

If $L>L_{P \max }$ or $L<L_{P \min }, P_{\text {arc max }}$ will be greater than $P_{\mathrm{CI}}$, and the IDD of the converter will have the capability to ignite methane-air mixtures in both conditions. According to Figure 13, the inductance design range based on power $L_{p}$ is given by the following:

$$
L_{P} \in\left[L_{P \min }, L_{P \max }\right] .
$$

As shown in Figure 11, $L_{P \max }$ decreases as $U_{\mathrm{i}}$ increases and $R_{L}$ decreases; $L_{P \text { min }}$ increases as $U_{\mathrm{i}}$ increases and $R_{L}$ decreases. Therefore, the values of $L_{P \text { max }}$ and $L_{P \text { min }}$ when the converter is operating in the $U_{i \max }$ and $R_{L \text { min }}$ conditions should be considered in the design.

According to Figure 12, there is a maximum inductance based on the energy $L_{W \text { max }}$, which is shown in Figure 14. If $L>L_{W \text { max }}, W_{L}$ will be greater than $W_{\mathrm{LCI}}$. Thus, the converter IDD will have the capability to ignite methane-air mixtures.

By incorporating Figure 14, the inductance design range based on the energy $L_{W}$ is given by the following:

$$
L_{W} \in\left[0, L_{W \max }\right]
$$

From Figure 12, $L_{W \max }$ decreases as $U_{\mathrm{i}}$ and $R_{L}$ increase. Therefore, the value of $L_{W \max }$ when the converter is operating in the $U_{i \min }$ and $R_{L \text { min }}$ conditions should be considered in the design. 
TABLE 2: Error of $W_{\text {LCI }}$ between regression expression and MIC.

\begin{tabular}{lcccc}
\hline$U_{i}(\mathrm{~V})$ & $I_{L P}(\mathrm{~A})$ & $W_{\text {LCI }}$ by equation $(21)(\mu \mathrm{J})$ & $W_{\text {LCI }}$ by MIC $(\mu \mathrm{J})$ & Relative error $(\%)$ \\
\hline 8 & 0.3 & 525 & 517 & 1.55 \\
8 & 1 & 771.44 & 750 & 2.86 \\
8 & 3 & 1224.33 & 587.5 & 0.77 \\
12 & 0.5 & 568.5 & 700 & 3.18 \\
12 & 1 & 730.44 & 1057.5 & 4.35 \\
12 & 3 & 1085.78 & 537.5 & 2.67 \\
18 & 0.5 & 539.82 & 575 & 0.43 \\
18 & 1 & 589.27 & 652.5 & 2.48 \\
18 & 3 & 677.09 & & 3.77 \\
\hline
\end{tabular}

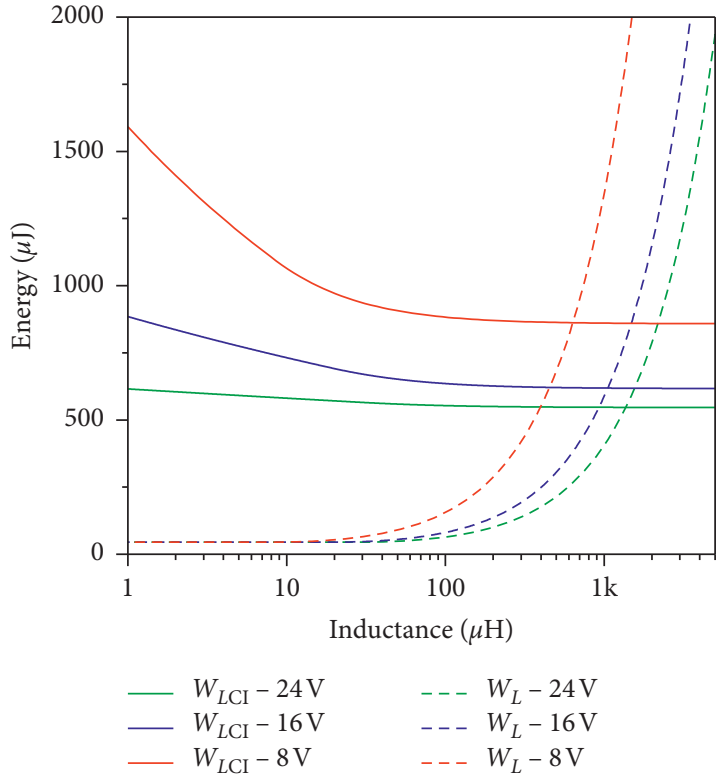

(a)

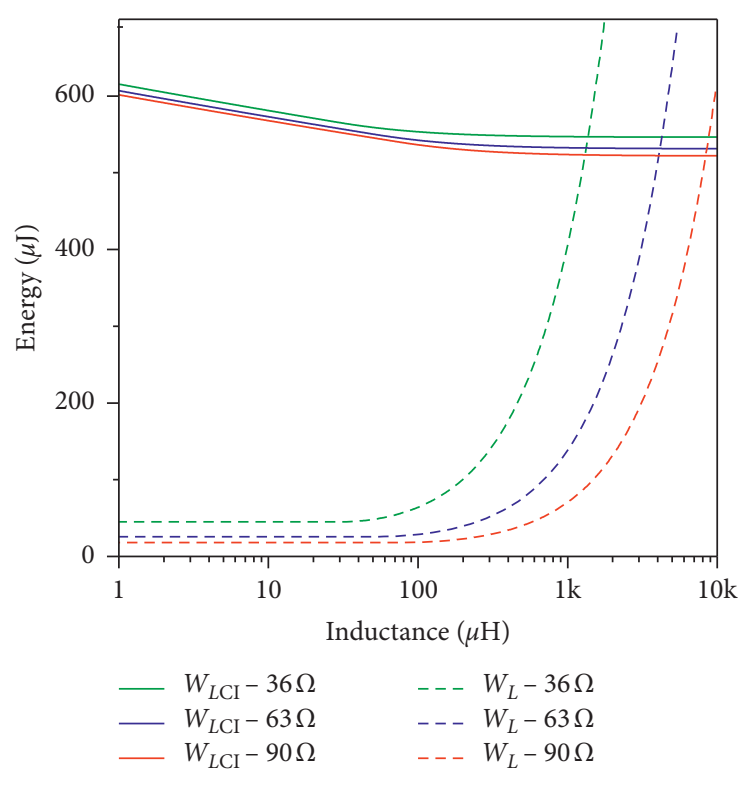

(b)

Figure 12: $W_{\mathrm{LCI}}$ and $W_{L}$ vs. $L$ and $U_{\mathrm{i}}$. (a) Different $U_{i}\left(T=200 \mu \mathrm{s}, U_{o} U_{\mathrm{o}}=18 \mathrm{~V}, R_{L}=36 \Omega\right.$, and $f=200 \mathrm{kHz}$ ). (b) Different $R_{L}$ ( $T=200 \mu \mathrm{s}$, $U_{o}=18 \mathrm{~V}, U_{i}=20 \mathrm{~V}$, and $\left.f=200 \mathrm{kHz}\right)$.

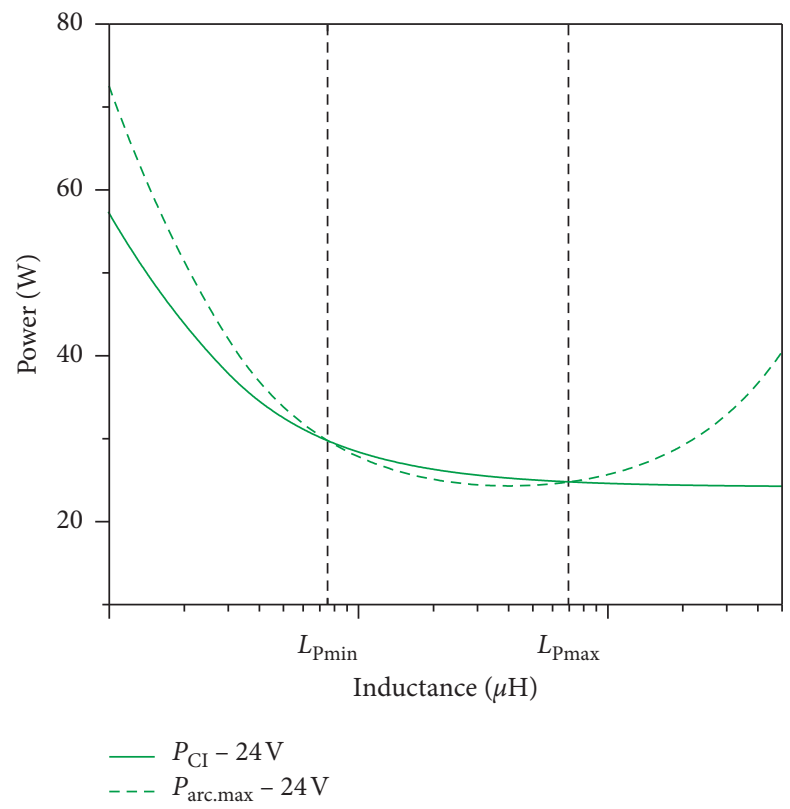

Figure 13: The inductance design range based on power ( $T=200 \mu \mathrm{s}, U_{o}=18 \mathrm{~V}, R_{L}=36 \Omega$, and $f=200 \mathrm{kHz}$ ). 


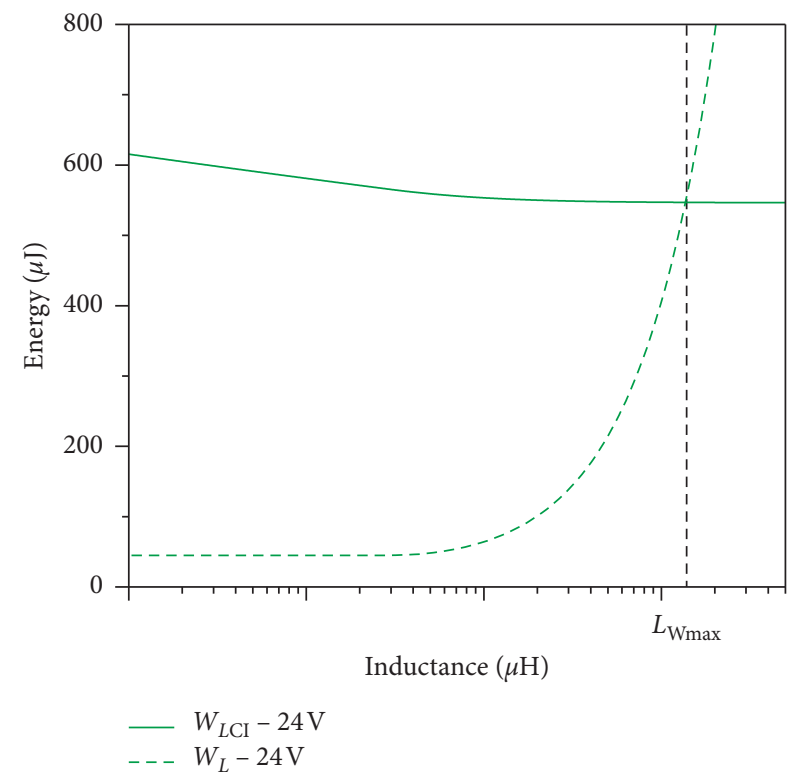

inductance $L_{\text {opt }}$ that maximizes the power difference $P_{\Delta}$ between $P_{\mathrm{CI}}$ and $P_{\text {arcmax }}$ when the converter operates in the $U_{i \max }$ and $R_{L \text { min }}$ conditions. Thus, this inductance will cause the buck-boost converter to have the maximum safety margin of the inner-intrinsic safety performance based on power.

Since $L>L_{E \min }$, the converter works in the CCM when $R_{L}=R_{L \text { min }}$. According to equation (19), the power difference $P_{\Delta}$ can be obtained by the following:

$$
P_{\Delta}=\left(12.25 I_{L P C C M}^{-(25 / 31)}-U_{i \max }-L \frac{I_{L P C C M}}{T}+14\right) I_{L P C C M}
$$

For the first derivative of equation (24) is equal to zero, we can obtain

Figure 14: The inductance design range based on energy $\left(T=200 \mu \mathrm{s}, U_{o}=18 \mathrm{~V}, R_{L}=36 \Omega\right.$, and $\left.f=200 \mathrm{kHz}\right)$.

3.6. Inductance Optimization Based on Inner-Intrinsic Safety Demands. According to Figure 13, there is an optimal

$$
\begin{aligned}
& \frac{4.94 U_{\mathrm{i}} U_{\mathrm{o}}}{L^{2} f\left(U_{\mathrm{i}}+U_{\mathrm{o}}\right)} I_{L P C C M}^{-(25 / 31)}+\frac{U_{i}^{2} U_{\mathrm{o}}}{2 L^{2} f\left(U_{\mathrm{i}}+U_{\mathrm{o}}\right)}+\frac{I_{L P C C M} U_{\mathrm{i}} U_{\mathrm{o}}}{L T f\left(U_{\mathrm{i}}+U_{\mathrm{o}}\right)}-\frac{I_{L P C C M}^{2}}{T(L)} \\
& \quad+\frac{I_{L P C C M} U_{\mathrm{i}} U_{\mathrm{o}}}{T(L) L f\left(U_{\mathrm{i}}+U_{\mathrm{o}}\right)}+\frac{I_{L P C C M}^{2} L[T(L)]^{\prime}}{[T(L)]^{2}}-\frac{U_{\mathrm{i}} U_{\mathrm{o}}\left(12.25 I_{L P C C M}^{-(25 / 31)}+14\right)}{2 L f\left(U_{\mathrm{i}}+U_{\mathrm{o}}\right)}=0,
\end{aligned}
$$

where $T(L)$ represents the discharge time $T$ affected by the inductance $L$. The root of equation (25) is the optimal inductance $L_{\text {opt }}$ that maximizes the power difference $P_{\Delta}$.

To investigate the influence of $U_{\mathrm{i}}$ on the design and optimization of inductance, the laws governing the change in $L_{P}, L_{W}, L_{E \min }$, and $L_{\text {opt }}$ with $U_{\mathrm{i}}$ are shown in Figure 15. The discharge time $T$ can be determined from the IDD time model based on the IEC spark test apparatus [27], which is given by

$$
T(L)=\left(2.98+1.66 \times 10^{3} L+221.37 I_{L P}-119.38 I_{L P}^{2}-25.67 I_{L P}^{3}+24.1 I_{L P}^{4}\right) \times 10^{-6}
$$

In Figure 15, the shaded area is the design range in which the inductance $L$ meets the demands of inner-intrinsic safety and electric performance. To ensure that the IISBBC has the best inner-intrinsic safety performance in the most dangerous condition, the inductance $L$ should be as close to $L_{\text {opt }}$ as possible.

\section{Experimental Verification}

4.1. Design of the Inner-Intrinsically Safe Buck-Boost Converter. Two groups of the main system and component parameters of the IISBBC are shown in Table 3.
According to Figure 15 and Table 3, in these parameters, when $U_{\mathrm{i}}$ is higher than $24 \mathrm{~V}, L$ will have no value to meet the electrical performance and inner-intrinsic safety demands. Therefore, considering the working demands and voltage fluctuations, $U_{\mathrm{i}}$ of the IISBBC is set to $14-22 \mathrm{~V}$ and divided into two groups of low-input voltage (Group 1) and highinput voltage (Group 2). Taking Group 1 as an example, the design steps are as follows:

(1) According to the above parameters and equation (8), the inductance $L$ must be greater than $L_{E \text { min }}$, which is given by the following: 


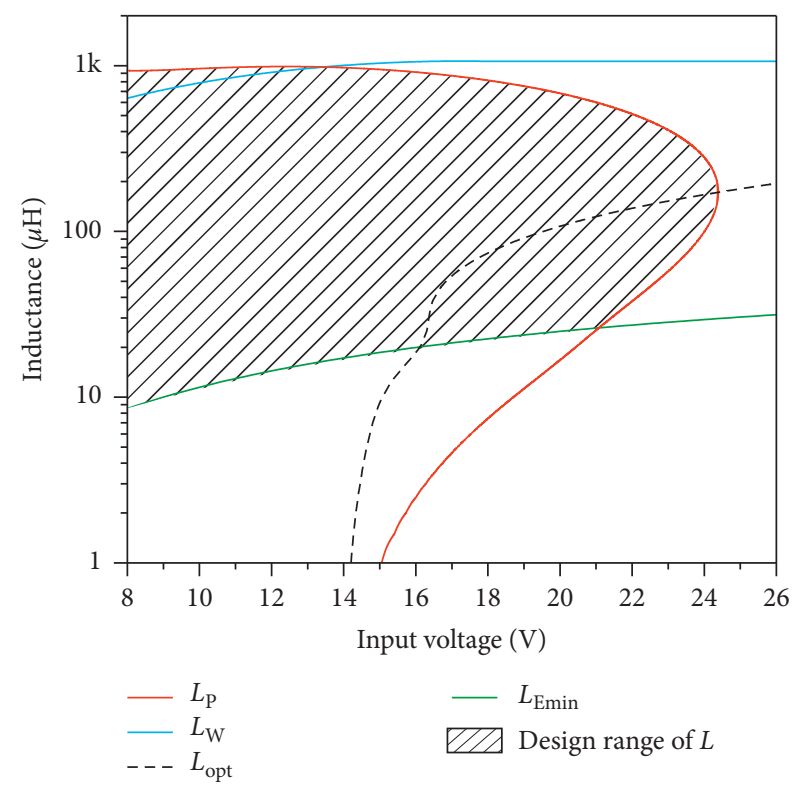

FIgURE 15: $L_{P}, L_{W}, L_{E \min }$, and $L_{\text {opt }}$ vs. $U_{i}\left(U_{o}=18 \mathrm{~V}, R_{L}=36 \Omega\right.$, and $f=200 \mathrm{kHz}$ ).

TABLE 3: Main system and component parameters.

\begin{tabular}{lcc}
\hline Variables & Group 1 & Group 2 \\
\hline$U_{i}$ & $14-18 \mathrm{~V}$ & $18-22 \mathrm{~V}$ \\
$U_{o}$ & $18 \mathrm{~V}$ & $18 \mathrm{~V}$ \\
$R_{L}$ & $36-90 \Omega$ & $36-90 \Omega$ \\
$f$ & $200 \mathrm{kHz}$ & $200 \mathrm{kHz}$ \\
$U_{\mathrm{PP}}$ & $1 \% U_{o}$ & $1 \% U_{o}$ \\
\hline
\end{tabular}

$$
L \geq L_{E \min }=\frac{R_{L \min } U_{i \max }^{2}}{2 f\left(U_{i \max }+U_{\mathrm{o}}\right)^{2}}=22.5 \mu \mathrm{H} .
$$

(2) The inductance $L$ must ensure that there is no IDD ignition capability when the converter operates at $U_{i \max }$ and $R_{L \text { min }}$ based on the arc power. Since $L>L_{E \min }$, the converter works in the CCM when $R_{L}=R_{L \min }$. Combining equations (2) and (19), the maximum inductance $L_{P \max }$ and the minimum inductance $L_{P \text { min }}$ based on the arc power can be obtained by

$$
U_{i \max } I_{L \mathrm{PCCM}}+L \frac{I_{L \mathrm{PCCM}}^{2}}{T}=\left(12.25 I_{L \mathrm{PCCM}}^{-(25 / 31)}+14\right) I_{L \mathrm{PCCM}} .
$$

Solving equation (28), we obtain the following:

$$
\left\{\begin{array}{l}
L_{P \min }=7.51 \mu \mathrm{H} \\
L_{P \max }=813.92 \mu \mathrm{H} .
\end{array}\right.
$$

According to equation (22), the inductance design range based on power $L_{p}$ is given by the following:

$$
7.51 \leq L_{P} \leq 813.92 \mu \mathrm{H} \text {. }
$$

(3) The inductance $L$ must ensure that there is no IDD ignition capability when the converter operates at $U_{i \text { min }}$ and $R_{L \text { min }}$ based on the arc energy. Since the expression of $W_{\mathrm{LCI}}$ is different according to $U_{\mathrm{i}}$ and $I_{L P}$, the minimum inductance peak current $I_{L P \text { min }}$ needs to be determined. According to equation (2), $I_{L P}$ decreases to $I_{L P \min }$ when $L$ is infinite, which is given by the following:

$$
I_{L P \min }=\frac{U_{\mathrm{o}}\left(U_{i \min }+U_{\mathrm{o}}\right)}{R_{L \min } U_{i \min }}=1.14 \mathrm{~A}>0.4 \mathrm{~A} .
$$

Combining equations (12) and (21) and substituting the parameters, the maximum inductance based on the energy $L_{W \max }$ can be obtained by

$$
L_{W \max }=3.28 I_{L \mathrm{PCCM}}^{2}\left(2.5 I_{L \mathrm{PCCM}}\right)^{-1.596-0.012 \exp \left(0.187 U_{\mathrm{i}}\right)} \times 10^{-3} .
$$

Solving equation (32), we obtain

$$
L_{W \max }=1003.11 \mu \mathrm{H} \text {. }
$$

According to equation (23), the inductance design range based on the energy $L_{W}$ is given by the following:

$$
0 \leq L_{W} \leq 1003.11 \mu \mathrm{H}
$$

(4) According to equations (25) and (26), the optimal inductance $L_{\mathrm{opt}}$ is as follows:

$$
L_{\text {opt }}=74.05 L \mu \mathrm{H} \text {. }
$$

To ensure that the IISBBC has the the best innerintrinsic safety performance, the inductance $L$ is taken as $L_{\text {opt }}$.

(5) According to equation (9), $C_{E \min }$ is $9.437 \mu \mathrm{F}$. Thus, we can set $C$ equal to $22 \mu \mathrm{F}$ to meet the electric performance demand.

Similarly, the inductance design range of Group 2 can be obtained. The inductance design ranges of these two groups of IISBBC are shown in Table 4.

The design ranges of inductance and capacitance obtained by the proposed method and design method based on the MIC [24] are compared in Table 5.

The design method based on the MIC takes $L_{E \text { min }}$ as the initial value, iterates by querying the MIC after considering the safety margin $\lambda(\lambda=1.5$ in Table 5), and obtains the maximum inductance that meets the inner-intrinsically safe performance demands. However, this method is more complicated, and reading errors may accumulate by querying the MIC multiple times; thus, the accuracy of the method is reduced. Moreover, according to Group 2 in Table 5, when $U_{\mathrm{i}}$ is large, there is a case where the critical ignition current $I_{\mathrm{MIC}}$ corresponding to $L_{E \min }$ fails to meet the intrinsic safety demand, and the iteration cannot be performed. Thus, the applicability of the method is also reduced. 
TABLE 4: Inductance design range of IISBBC.

\begin{tabular}{lcc}
\hline Variables & Group 1 $(\mu \mathrm{H})$ & Group 2 $(\mu \mathrm{H})$ \\
\hline$L_{E \min }$ & 22.5 & 28.225 \\
$L_{P \min }$ & 7.51 & 38.29 \\
$L_{P \max }$ & 813.92 & 508.98 \\
\hline$L_{W \max }$ & 1003.11 & 1100.11 \\
$L_{\mathrm{opt}}$ & 74.05 & 137.78 \\
\hline
\end{tabular}

TABLE 5: Comparison of the inductance and capacitance design ranges.

\begin{tabular}{lccc}
\hline & Variables & Proposed method & Method based on the MIC \\
\hline \multirow{2}{*}{ Group 1 } & $L$ & $22.5 \leq L \leq 813.92 \mu \mathrm{H}$ & $22.5 \leq L \leq 349.88 \mu \mathrm{H}$ \\
& $L_{\text {opt }}$ & $74.05 \mu \mathrm{H}$ & None \\
& $C\left(\right.$ if $\left.L=L_{\text {opt }}\right)$ & $9.437 \mu \mathrm{F} \leq C$ & $9.437 \mu \mathrm{F} \leq C$ \\
\hline Group 2 & $L$ & $38.29 \leq L \leq 508.98 \mu \mathrm{H}$ & N/A \\
& $L_{\text {opt }}$ & $137.78 \mu \mathrm{H}$ & \\
\hline
\end{tabular}

The proposed design method considers the effect of the critical ignition power and energy on the IDD ignition capability. According to the analysis of the critical ignition power, if $L$ is too large or too small, the IDD can ignite methane-air mixtures, which contradicts the idea of the design method based on the MIC that $L$ meets the intrinsically safe performance demand and should be as small as possible. Moreover, based on the principle that the converter has the largest safety margin of IDD, the optimal inductance $L_{\text {opt }}$ is obtained. Thus, the inductance design method is clearer. According to the analysis of the critical ignition energy, $W_{\mathrm{LCI}}$ is affected by $L, I_{L P}$, and $U_{\mathrm{i}}$. Therefore, the critical ignition energy $W_{\mathrm{CI}}$ is generally not considered to be constant. The main difference between these two methods is the design consideration based on the inner-intrinsic safety performance. However, the design considerations based on the electrical performance are basically identical, so the two methods have consistent $L_{E \min }$ and $C_{E \min }$.

4.2. Explosive Test Based on the IEC Spark Test Apparatus. The IISBBCs were tested by the IEC spark test apparatus. The IEC spark test apparatus [28] and its structure are shown in Figure 16, where the tungsten wire and the cadmium disk are the disconnected electrodes.

The disconnected points of the tested circuit are connected with these two electrodes. The disconnected electrodes are contacted and disconnected through the transmission gear rotates so that the circuit is turned on and off $[29,30]$.

The steps of the explosive test are as follows:

(1) Prepare a gas mixture corresponding to an explosive environment. The Type I environment is a methaneair mixture with a concentration ratio of $8-8.6 \%$. Clean the electrodes.

(2) Calibrate the sensitivity of the apparatus. The calibration circuit is a simple inductive circuit with parameters of supply voltage $E=24 \mathrm{~V}$, inductance
$L=95 \mathrm{mH}$, and current $I=110 \mathrm{~mA}$. If an explosion occurs within 400 revolutions of the transmission gear, the sensitivity calibration of the apparatus is qualified. The explosive evaluation of the tested circuit can be carried out only after the apparatus sensitivity has been calibrated three times.

(3) The IISBBC is connected to the resistive load and the IEC spark test apparatus for the explosive tests. If an explosion occurs within 400 revolutions of the transmission gear, the tested circuit has ignition capability; otherwise, it is intrinsically safe.

To verify the effectiveness of inductance optimization, the theoretical and experimental values of the difference $P_{\Delta}$ between the critical ignition power $P_{\mathrm{CI}}$ and the maximum arc power $P_{\text {arc.max }}$ under different $L$ are shown in Figure 17 .

According to Figure 17, the closer $L$ is to $L_{\text {opt }}$, the larger $P_{\Delta}$ is, and the maximum $P_{\Delta}$ is reached when $L$ is equal to $L_{\text {opt }}$. The inner-intrinsic safety performance of the IISBBC has the maximum safety margin based on the arc power, which proves the effectiveness of the inductance optimization.

However, it can be found that the margin of the test value is smaller than the theoretical value. This is due to the parasitic parameters of the converter, which makes the inductance peak current $I_{L P}$ greater than the theoretical value, which reduces the safety margin. However, the safety margin of $L_{\mathrm{opt}}$ is still the largest.

To verify the feasibility and reliability of the proposed design method, explosive tests were performed on buckboost converters with different inductances. The test results are shown in Table 6.

According to Table 5, when $L$ is within the design range that meets the inner-intrinsic safety performance demands, IDD will not have the ignition capability, which verifies the feasibility of the proposed design method.

Moreover, if $L$ is near the boundary between the innerintrinsic safety and dangerous range, it still does not have ignition capability. This is because the proposed method 


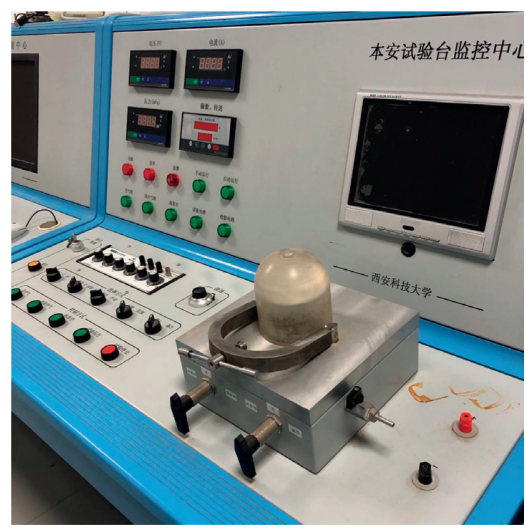

(a)

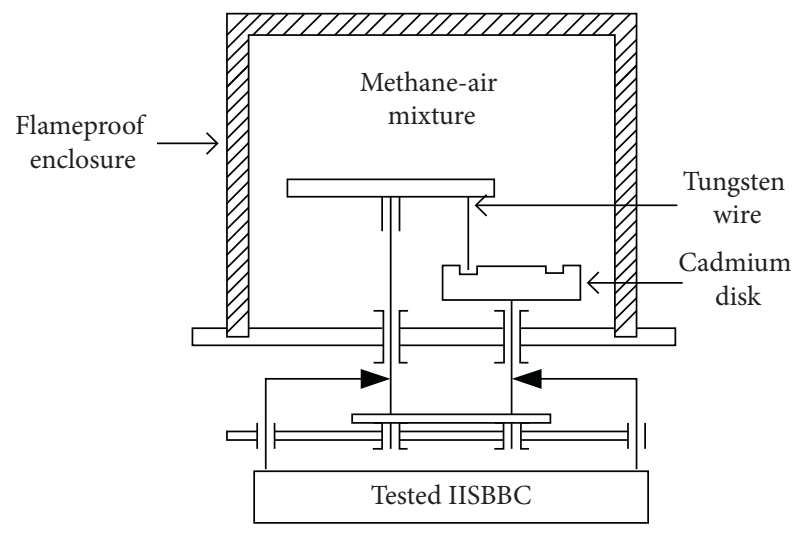

(b)

FIGURE 16: IEC spark test apparatus. (a) Prototype appearance. (b) Structural schematic.

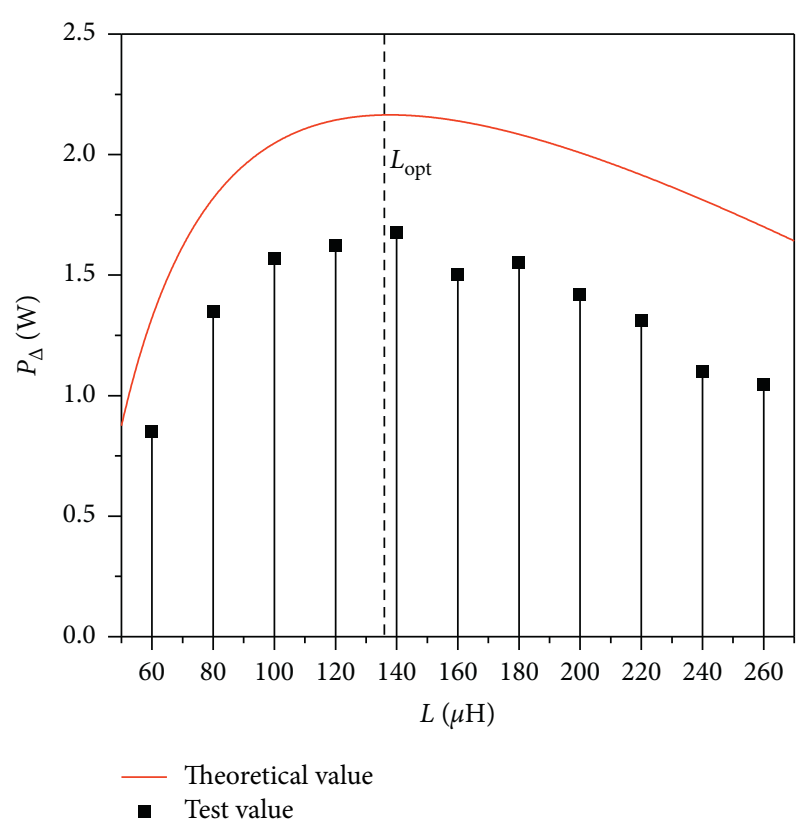

Figure 17: $P_{\Delta}$ vs. $L$ of the IISBBC in the explosive test $\left(U_{i}=22 \mathrm{~V}\right.$, $U_{o}=18 \mathrm{~V}, C=22 \mu \mathrm{F}, R_{L}=36 \Omega$, and $\left.f=200 \mathrm{kHz}\right)$.

TABle 6: Explosive test results $\left(U_{i}=22 \mathrm{~V}, U_{o}=18 \mathrm{~V}, C=22 \mu \mathrm{F}\right.$, $R_{L}=36 \Omega$, and $f=200 \mathrm{kHz}$ ).

\begin{tabular}{lccc}
\hline Design range & $\begin{array}{c}\text { Critical } \\
\text { value }\end{array}$ & $\begin{array}{c}\text { Inductance } \\
(\mu \mathrm{H})\end{array}$ & Results \\
\hline Unsafe & & 20 & Exploded \\
& & 35 & Unexploded \\
\hline \multirow{2}{*}{ Inner-intrinsically } & $L_{P \text { min }}$ & 38.29 & Unexploded \\
safe & & 50 & Unexploded \\
& $L_{\text {opt }}$ & 137.78 & Unexploded \\
& $L_{P \max }$ & 508.98 & Unexploded \\
& & 520 & Unexploded \\
Unsafe & & 900 & Exploded \\
& $L_{W \max }$ & 1095.11 & Exploded \\
& & 1500 & Exploded \\
\hline
\end{tabular}

considers the most dangerous condition, and the actual IDD ignition capability is weaker than this condition, so it has a safety margin, which verifies the reliability of the proposed design method.

However, the proposed design method does not consider the output intrinsic safety performance of the converter, so further research on this is needed.

\section{Conclusion}

(1) The most dangerous IDD condition of the buckboost converter is that IDD occurs when $i_{L}$ is equal to $I_{L P}$ and the switch remains on. In this condition, a resistive circuit model with a controlled voltage source is proposed to represent the buck-boost converter.

(2) Expressions describing the IDD ignition capability of the buck-boost converter in terms of the critical ignition power and energy were derived. $P_{\mathrm{CI}}$ decreases with increasing $R_{L}$ and $L$, is independent of $U_{\mathrm{i}}$ in the DCM, and decreases with increasing $U_{\mathrm{i}}$ in the CCM. $P_{\text {arcmax }}$ decreases with increasing $R_{L}$, increases with increasing $U_{\mathrm{i}}$ when $L$ is small, decreases with increasing $U_{\mathrm{i}}$ when $L$ is large, and first decreases and then increases with increasing $L . W_{\mathrm{LCI}}$ and $W_{L}$ decrease with increasing $U_{\mathrm{i}}$ and $R_{L} ; W_{\mathrm{LCI}}$ decreases and tends to be stable with increasing $L$; $W_{L}$ increases with increasing $L$ and $I_{L P}$ and decreasing $U_{\mathrm{i}}$. Therefore, the IDD has the strongest ignition capability based on power when the buckboost converter operates in the $U_{i \max }$ and $R_{L \text { min }}$ conditions and has the strongest ignition capability based on energy when the converter operates in the $U_{i \text { min }}$ and $R_{L \text { min }}$ conditions. When $P_{\text {arc max }} \geq P_{C I}$ or $W_{L} \geq W_{\text {LCI }}$, the IDD of the buck-boost converter will have the capability to ignite methane-air mixtures; thus, the converter is inner-intrinsically safe only when $P_{\text {arc.max }}<P_{\mathrm{CI}}$ and $W_{L}<W_{\mathrm{LCI}}$.

(3) The optimal method for designing an IISBBC to meet the demands of electric and inner-intrinsic safety performance was obtained. Based on this method, 
the ranges of $L, C$, and $L_{\text {opt }}$ to design an IISBBC with the best inner-intrinsic safety performance can be obtained. The increased applicability of the proposed optimal design method compared with the design method based on querying the MIC was shown; the accuracy, feasibility, and reliability of the proposed optimal design method were demonstrated by comparison in explosion tests based on the IEC spark test apparatus.

\section{Data Availability}

The data used to support the findings of this study are included within this article.

\section{Conflicts of Interest}

The authors declare that there are no conflicts of interest regarding the publication of this paper.

\section{Acknowledgments}

This work was supported by the National Natural Science Foundation of China (nos. 51604217 and 51777167).

\section{References}

[1] M. Aniruddh, -J. Mauger Mickael, K. Prasad, and D. Divan, "Intrinsically-safe modular power converters for electric transportation," in Proceedings of the 2020 IEEE Transportation Electrification Conference and Expo, June 2020.

[2] S. Jitendra-Kumar, G. Banerjee, S. Arvind-kumar et al., "Modelling of design parameters of intrinsically safe instruments for the safety of oil, gas and coal industries," International Journal of Oil Gas and Coal Technology, vol. 22, no. 3, pp. 417-431, 2019.

[3] M. Qing-Hai and W. Huang, "Calculation and analysis of residual energy storage in intrinsically safe BUCK converter," in Proceedings of the 2019 22nd International Conference on Electrical Machines and Systems (ICEMS), pp. 1-4, IEEE, Harbin, China, August 2019.

[4] V.-V. Ryzhov, O.-N. Molokanov, P.-A. Dergachev et al., "Simulation of the low-voltage DC arc," in Proceedings of the 1st IEEE International Youth Conference on Radio Electronics, Electrical and Power Engineering, IEEE, Moscow. Russia, March 2019.

[5] Y. Wang, Y.-H. Qiao, H.-J. Zhang et al., "Transformerless ultrasonic ranging system with the feature of intrinsic safety for explosive environment," Sensors, vol. 18, no. 12, 2018.

[6] S. K. Kundu, J. Zanganeh, D. Eschebach, and B. Moghtaderi, "Explosion severity of methane-coal dust hybrid mixtures in a ducted spherical vessel," Powder Technology, vol. 323, pp. 95-102, 2018.

[7] D. Razus, C. Movileanu, and D. Oancea, "Additive influence on ignition of stoichiometric ethylene-air mixture by break sparks," Fuel, vol. 232, pp. 134-140, 2018.

[8] C. Uber, M. Hilbert, A. Felgner, D. Hüser, M. Kurrat, and U. Gerlach, "Electrical discharges caused by opening contacts in an ignitable atmosphere - Part I: analysis of electrical parameters at ignition limits," Journal of Loss Prevention in the Process Industries, vol. 61, pp. 114-121, 2019.

[9] C. Uber, T. Runge, J. Brunzendorf, M. Kurrat, and U. Gerlach, "Electrical discharges caused by opening contacts in an ignitable atmosphere-part II: spectroscopic investigation and estimation of temperatures," Journal of Loss Prevention in the Process Industries, vol. 61, no. 2019, pp. 213-219, 2019.

[10] C. Uber, R. Shekhar, A. Felgner, L. Koenders, and U. Gerlach, "Experimental investigation of low-voltage spark ignition caused by separating electrodes," Journal of Loss Prevention in the Process Industries, vol. 49, no. 2017, pp. 822-831, 2017.

[11] S. Liu, H. Wu, C. Wang, S. Nie, and L. Qi, "Inner intrinsically safe criterion and design considerations of buck converter based on equivalent inductance," Electric Power Components and Systems, vol. 47, no. 3, pp. 248-260, 2019.

[12] L. I. Jing and J.-J. Liu, "A novel buck-boost converter with low electric stress on components," IEEE Transactions on Industrial Electronics, vol. 66, no. 4, pp. 2703-2713, 2019.

[13] L. I. Peng-Cheng, C.-J. Zhang, Z.-Z. Kan et al., "An integrated buck-boost CLLC bidirectional DC converter with high gain and soft switching," Zhongguo Dianji Gongcheng Xuebao/ Proceedings of the Chinese Society of Electrical Engineering, vol. 38, no. 11, pp. 3295-3305, 2018.

[14] M. Venmathi, V. Krishnakumar, C. Bharatiraja, and V. VasanPrabhu, "A modified buck-boost zero voltage switching converter for photo-voltaic applications," in Proceedings of the 2018 IEEE International Conference on Power Electronics, Drives and Energy Systems, pp. 1-6, IEEE, Chennai, India, December 2018.

[15] X. Hong, J. Wu, and C. Wei, "98.1\%-efficiency hystereticcurrent-mode noninverting buck-boost DC-DC converter with smooth mode transition," IEEE Transactions on Power Electronics, vol. 32, no. 3, pp. 2008-2017, 2017.

[16] L. Jia, X. Sun, Z. Zheng, X. Ma, and L. Dai, "Multimode smooth switching strategy for eliminating the operational dead zone in noninverting buck-boost converter," IEEE Transactions on Power Electronics, vol. 35, no. 3, pp. 3106-3113, 2020.

[17] H. Sepideh, B. Jan, D. Jan et al., "A model for the minimum ignition energy of dust clouds," Process Safety and Environmental Protection, vol. 121, no. 2019, pp. 43-49, 2019.

[18] L. U. Hai-Tao, L. I. U. Fu-Qiang, K.-X. Wang et al., "Numerical study on the minimum ignition energy of a methaneair mixture," Fuel, vol. 285, 2021.

[19] D. Charles, P. Vassilios, F. Ahmed Samer et al., "On the minimum ignition energy and its transition in the localised forced ignition of turbulent homogeneous mixtures," Combustion and Flame, vol. 201, pp. 104-117, 2019.

[20] Y. Zhen-Yi, Y. U. Xiao, H. Zhu et al., "Effect of spark discharge energy scheduling on ignition under quiescent and flow conditions," Proceedings of the Institution of Mechanical Engineers Part D-Journal of Automobile Engineering, vol. 234, no. 12, pp. 2878-2891, 2020.

[21] M. Qing-Hai, M. U. Long-Hua, and C.-Lin Wang, "Electric power criterion of intrinsic safe circuits," Journal of China University of Mining and Technology, vol. 33, no. 3, pp. 292-294, 2004.

[22] S.-L. Liu and Y.-X. Zhao, "Research on short-circuit discharge characteristics of capacitive circuits based on safety spark test apparatus," Mathematical Problems in Engineering, vol. 30, no. 1, pp. 135-142, 2014.

[23] S.-L, Liu, M. A. Yi-Bo, X.-M. Wen et al., "Research on the most dangerous output Short-circuit discharge conditions of output intrinsic safety buck-boost converters," Transactions of China Electrotechnical Society, vol. 30, no. 14, pp. 253-260, 2015.

[24] J.-M. Zhong, Intrinsical Safety Behavior \& Design Considerations of Buck-Boost Converter, Xi'an University of Science \& Technology, Xi'an, China, 2006. 
[25] S.-L. Liu, J. Liu, and J.-M. Zhong, "Analysis and design of output intrinsically safe buck-boost DC-DC converters," Proceedings of the CSEE, vol. 28, no. 3, pp. 62-67, 2008.

[26] IEC, Explosive atmospheres-part 11: equipment protection by intrinsic safety "i”: IEC 60079-11, 2011.

[27] Y.-X. Zhao, S.-L. Liu, M. Wang et al., "Arc resistance modeling of inductor-disconnected circuit based on safety spark test apparatus," Acta Electronica Sinica, vol. 45, no. 5, pp. 1078-1083, 2017.

[28] R. Shekhar, L. R. Boeck, C. Uber, and U. Gerlach, "Ignition of a hydrogen-air mixture by low voltage electrical contact arcs," Combustion and Flame, vol. 186, no. 2017, pp. 236-246, 2017.

[29] C. Uber, S. Rajiv, F. Andre et al., "Experimental investigation of low-voltage spark ignition caused by separating electrodes," Journal of Loss Prevention in the Process Industries, vol. 49, no. B, pp. 822-831, 2017.

[30] Y.-X. Zhao, Qi. Wang, and Y. Wang, "Arc equivalent resistance modeling of inductor-disconnected-discharged arc considering electrode breaking speed," Journal of China Coal Society, vol. 44, no. S2, pp. 754-762, 2019. 